\title{
CHARACTERIZATION OF SELF-HEATING IN STORED WASTE
}

\author{
Henry Persson, \\ SP Technical Research Institute of Sweden
}

\section{ABSTRACT}

A common cause of fires in large bulk storages is spontaneous combustion. This project aimed at creating a general test procedure and an evaluation methodology to obtain relevant risk parameters for different types of waste with respect to self-heating characteristics and the risk of spontaneous combustion. SLF (Shredder Light Fraction) from shredding of automobiles has been used as a pilot waste. The methodology is aiming at being used by e.g. the waste management sector in order to examine the propensity to self-heating of a specific waste fraction. Based on such characterization, storage could be better planned to avoid fires. The work of the project showed that with a combination of a relatively large scale test method $\left(1 \mathrm{~m}^{3}\right)$, and isothermal calorimetry one can study both how a material behaves regarding self-heating in bulk form and how the various constituent components affect self-heating. This means that these methods can give an indication on the cause of a specific fire, on which components of a given waste contribute to the self-heating, on how a particular mixture behaves in relationships to another, etc. In summary the developed methodology involves: 1) Representative sampling and characterization of the waste including grinding of subsamples for analysis by laboratory methods, 2) Analysis of heat generation from self-heating by isothermal calorimetry, 3) Determination of thermal properties of the waste bulk material by using a small-scale test method (TPS) for the heat capacity and for the effective thermal conductivity, 4) Large scale self-heating tests with the waste in its original fraction to provide information on critical temperatures for varying storage conditions.

\section{KEYWORDS}

Self-heating, Heterogeneous waste, Storage, Characterization methodology.

\section{INTRODUCTION}

The gradual shift from fossil fuels to different types of biofuels and waste fuels has resulted in much more extensive handling and storage of these products. Due to lower calorific value and bulk density compared to e.g. oil, increased volumes of fuel are needed for a given amount of energy. Since the material is to be used as a high-grade fuel, higher requirements are placed on the storage technology. Industry handling and storage are also often focused on maximum efficiency and thereby very large production and handling facilities with large stocks will be required.

A study funded by the Swedish Fire Research Board (BRANDFORSK) in 2008 provided an overview of different types of biofuels and waste fractions, future trends, and various types of 
storage but also the new risks that could be a result of this change. Based on the study, a comprehensive research programme was proposed with the overall goal to achieve improved safety in the handling and storage of biomass and waste. The proposed program included a variety of suggestions for research activities with the overall objective to develop recommendations on fire safety during storage which can be beneficial for industry, emergency services and other relevant authorities. One of the suggested activities was to in more detail study the situation today when it comes to fire safety in relation to handling and storage of biofuels and waste.

The study presented here has been focused on gathering more detailed information on how various biofuels and waste fractions are handled and stored by the industry, to provide an updated fire statistics on fires which occur in these facilities and to compile examples of experience and lessons learned from some real fires.

\section{MSB FIRE STATISTICS}

Fire statistics has been compiled using the MSB (Swedish Civil Contingencies Agency) data base which is covering all alarms, about 25000 per year, to the Swedish fire and rescue services, which includes not only fires but also traffic accidents, and other rescue operations. The incident report sent to MSB from each alarm includes a lot of information making it possible to categorize the incidents, and based on further subdivisions and by searching for certain key words, there is a possibility to identify fires of specific interest. In this project it was searched for fires in industry applications which involved biofuels or waste, mainly during the period 2005-2012.

Table 1. Total number of fires fulfilling the search criteria’s for 2005-2012

\begin{tabular}{|l|l|l|l|}
\hline Year & $\begin{array}{l}\text { Total number of } \\
\text { fires }\end{array}$ & $\begin{array}{l}\text { Fires in } \\
\text { buildings }\end{array}$ & Outdoor fires \\
\hline 2005 & 562 & 157 & 405 \\
\hline 2006 & 608 & 158 & 450 \\
\hline 2007 & 646 & 170 & 476 \\
\hline 2008 & 676 & 183 & 493 \\
\hline 2009 & 610 & 166 & 444 \\
\hline 2010 & 464 & 168 & 296 \\
\hline 2011 & 545 & 155 & 390 \\
\hline 2012 & 488 & 148 & 340 \\
\hline
\end{tabular}

As presented in the Table 1, the total number of fires fulfilling the search criteria's during 20052012 varied from 464 to 676 and the general trend is indicating a decrease since 2008. The number of fires connected to buildings varied from 148 to 183 and outdoor fires from 296 to 493.

In many cases the fires included in the statistics in Table 1 were not relevant for our project (not industry related) even though the search criteria were fulfilled. In order to get more certain data on the number of fires, all reported data from the fires during 2012 (488 fires) were studied in detail and only those that for sure were relevant for our project were selected. 
Linnaeus ECO-TECH '14,

Kalmar, Sweden, November 24-26, 2014

Table 2. Detailed study of the relevance of the reported fires during 2012

\begin{tabular}{|l|l|l|l|l|}
\hline Fires 2012 & Relevant & Uncertain & Not relevant & Total \\
\hline Fires in buildings & 38 & 56 & 54 & 148 \\
\hline Outdoor fires & 116 & 58 & 166 & 340 \\
\hline Total & 154 & 114 & 220 & 488 \\
\hline
\end{tabular}

As shown in Table 2, 154 fires were considered "relevant", 220 were considered "not relevant" and the remaining 114 fires were considered "uncertain". In these cases, detailed information was lacking to judge whether they were relevant or not. Of the 154 relevant fires, 38 occurred in buildings while 116 were outdoor fires. Spontaneous ignition was the most common reported cause for the fires, both in buildings (14 of 38) and in outdoor fires (74 of 116).

\section{INDUSTRY QUESTIONNAIRE}

In order to collect information on typical handling and storage of biofuels and waste, a questionnaire was distributed to about 280 industries/ storage facilities. The questionnaire included about 80 questions in total, asking for information about type of material, total quantities handled per year, and which type of storage was used for various materials/fractions, etc. The questionnaire also involved questions about number of incidents at the facility, both smaller incidents handled by their own personnel and more serious incidents where the fire and rescue service was alarmed, cause of fire, extinguishing tactics, etc. In total, 81 respondents answered the questionnaire, $42 \%$ of these handle both biofuels and waste, $21 \%$ only waste and $37 \%$ only biofuels/biomass. The most common material fractions among the respondents were industrial waste, wood chips from forest residues and recycled wood and the most common type of storage was outdoor in non-compacted piles. Much detailed data is also available on various storage (outdoor and indoor), such as the size/volume of the storage and storage time, but also distances between storage piles.

Most of the respondents answered that they never had experienced a fire situation, but there were also examples where they reported a fire frequency of 3-8 fires /year which were handled by their own personnel. The most common types of fires were in outdoor storage, process machinery and conveyor systems. The number of reported fires resulting in an extinguishing operation by the fire and rescue services during 2003-2012 varied from about 15 fires/year (2003-2006) to 46 reported fires during 2012. Based on the MSB statistics, the most likely cause for this trend is probably not a significant increase in fires but rather a problem of keeping record of incidents several years back.

\section{EXPERIENCE FROM REAL FIRE INCIDENTS}

A number of real fire incidents from various types of industries have been studied more in detail to obtain more information about e.g. the cause of the fire, the fire development and the fire fighting operation. Efforts have also been made to describe the lessons learned from the fire and what kind of measures that have been taken as a result of the fire, both technical and operational, to prevent the same incident to happen again. This might provide important information for similar industries and give them ideas about possible fire prevention measures.

\section{CONCLUSIONS}

The project has provided an extensive knowledge about the existing situation regarding handling and storage of biofuels/biomass and waste and the problems related to fire safety. This data will be 
of great importance and could partly form the base for future guidelines but also to identify areas where further research is needed.

\section{ACKNOWLEDGEMENT}

The project was funded by BRANDFORSK (project 701-121) with contribution from SP Technical Research Institute of Sweden. We would also like to thank all respondents to our questionnaire, the assistance from MSB and the members of the project reference group. 